\title{
In-group and out-group membership mediates anterior cingulate activation to social exclusion
}

\author{
Austen Krill ${ }^{1 *}$ and Steven M. Platek ${ }^{2}$ \\ School of Biological Sciences, The University of Liverpool, Liverpool, UK \\ School of Liberal Arts, Georgia Gwinnett College, Lawrenceville, Georgia, USA
}

Edited by:

Robin Dunbar, Oxford University, UK

Reviewed by:

Todd Shackelford, Florida Atlantic

University, USA

Tom Schoenemann, James Madison

University, USA

*Correspondence:

Austen Krill, School of Biological Sciences, The University of Liverpool,

Crown St., Liverpool, L69 7ZB, UK.

e-mail: alkrill@liv.ac.uk

Steven M. Platek, School of Liberal

Arts, Georgia Gwinnett College,

Lawrenceville, GA 30043, USA.

e-mail:splatek@gmail.com
Functional magnetic resonance imaging was employed to examine sensitivity to social exclusion in three conditions: same-race, other-race, and self-resembling faces. The anterior cingulate cortex (ACC), specifically the dorsal ACC, has been targeted as a key substrate in the physical and social pain matrix and was hypothesized to regulate activation response to various facial conditions. We show that participants demonstrated greatest ACC activation when being excluded by self-resembling and same-race faces, relative to other-race faces. Additionally, participants expressed greater distress and showed increased ACC activation as a result of exclusion in the same-race condition relative to the other-race condition. A positive correlation between implicit racial bias and activation in the amygdala was also evident. Implicit attitude about other-race faces partly explains levels of concern about exclusion by out-group individuals. These findings suggest that individuals are more distressed and their brain (i.e. neural alarm system) responds with greater activation when being excluded by individuals whom they are more likely to share group membership with.

Keywords: social exclusion, fMRI, race, anterior cingulate cortex

\section{INTRODUCTION}

People have a powerful need to belong in a social group and they spend a great deal of time developing and maintaining social relationships (Baumeister and Leary, 1995). When social relationships are threatened by exclusion, people have a negative emotional response (Williams et al., 2000). Neural substrates involved in response to physical pain are also activated when a person is excluded or experiencing social pain (Coghill et al., 2003; Eisenberger and Lieberman, 2004; Eisenberger et al., 2003, 2005; Panksepp, 2005; Rainville et al., 1997). The dorsal anterior cingulate cortex (dACC) is one component of a more generalized pain matrix that is responsible for acting as a "neural alarm system" (Botvinick et al., 2001; Eisenberger and Lieberman, 2004; Ocshner et al., 2008) when one is experiencing physical or emotional pain. Specifically, the dACC is linked to the affective (but not the physical) distress response associated with pain (Rainville et al., 1997). Negative reactions to social pain, such as social exclusion, are pervasive. Research has demonstrated that the experience of exclusion is robust, because the neural correlates of exclusion persisted even when participants observed a scenario that emulated exclusion (Eisenberger et al., 2003). This suggests that, imagined exclusion evokes reactions similar to actual exclusion (Eisenberger and Lieberman, 2004; Eisenberger et al., 2003; Williams, 1997).

We conducted a functional magnetic resonance imaging (fMRI) study to examine how responses to social exclusion would be impacted by appearance of the excluder. Specifically, we investigated how level of resemblance to one's self impacted activation associated with being excluded. Participants experienced exclusion in three conditions: same-race face, other-race face, and selfresembling face. There were three main aims in this study. The first was to investigate how brain activation to exclusion would differ across the three conditions when playing Cyberball, a three person ball toss game that can be programmed to exclude participants. We hypothesized that participants would show the greatest level of activation in the dACC when they were excluded during the self-resemblance condition relative to the other conditions (selfresemblance $>$ same-race $>$ other-race). This hypothesis is guided by evidence suggesting that, in humans, self-facial resemblance appears to act as a kin detection mechanism (Daly and Wilson, 1982; Platek, 2002; Platek and Thomson, 2007; Platek et al., 2003, 2004, 2005). Self-resembling faces are perceived more favourably (Daly and Wilson, 1982; Platek et al., 2004), rated as more trustworthy (DeBruine, 2002; Platek and Thomson, 2007; Platek et al., 2009) and more attractive (DeBruine, 2004) compared to non-self-resembling faces (see also Platek et al., 2008). Self-face resemblance might unconsciously tap cues of kinship producing stronger feelings of cohesion with, and hence greater distress as a result of exclusion from, this group.

We also reasoned that there would be increased brain activation in the same-race condition as compared to the other-race condition because same-race faces represent in-group membership whereas other-race faces represent out-group membership (Platek et al., 2008). People respond differently to same-race faces relative to other-race faces (Cunningham et al., 2004; Golby et al., 2001; Hart et al., 2000; Herrmann et al., 2007; Kim et al., 2006; Lieberman et al., 2005; Love, 2001; Meissner and Brigham, 2001; Phelps, 2000; Pinkham et al., 2008; Platek et al., 2008; Stahl et al., 2008; Tanaka et al., 2004). Because brain mechanisms can quickly categorize faces by race (Platek et al., 2008), this can be an important component of socially-based judgements, which are combined with in- and out-group facial stimuli. If the brain is able to quickly process faces, with respect to race or group membership, then that information 
should be utilized when making decisions about behaviour during social interactions.

The second aim of the study was to determine whether levels of self-reported distress as a result of being excluded correlated with the brain activation. Previous studies have shown a positive correlation with self-reported distress and dACC activation during social exclusion (Eisenberger et al., 2003, 2005). Behavioural investigations of social exclusion have revealed that targets of exclusion report a decrease in satisfaction of four fundamental needs: belonging, self-esteem, control, and meaningful existence (Williams et al., 2000; Zadro et al., 2004). In accordance with our first hypothesis, we predicted that when participants were excluded in the self-resembling condition they would report greater distress relative to the other face conditions.

The final aim of the study was to test for a correlation between amygdala activation during exclusion and the effect of implicit racial bias (same-race vs other-race). While we have focused mainly on the ACC as our region of interest, the amygdala plays a very important role in implicit responses to racial groups (Phelps et al., 2000). Therefore, we felt that it was important to examine amygdala activation in this study. People tend to show implicit racial bias in favour of their own race even if they explicitly express no bias for or against other-race faces. For example, when participants are asked to categorize a same-race face as good, they are quick to do so. However, when asked to categorize an other-race face as good, they are considerably slower (Dasgupta et al., 2000; Greenwald and McGhee, 1998; Phelps, 2000). We hypothesized that as implicit racial bias increased, activation would decrease in the ACC but increase in the amygdala. A decrease in ACC activation would suggest that participants who are more racially biased are less distressed by exclusion in the otherrace condition; however amygdala activation may increase because viewing members of different social groups activates the amygdala which is thought to be related to social evaluation taking place at the unconscious level (Phelps et al., 2000).

\section{MATERIALS AND METHODS PARTICIPANTS}

Fourteen Caucasian (three males; nine females; mean $_{\text {age }}=27.9$; $\left.\mathrm{SD}_{\text {age }}=11.7\right)$ participants from a Northwestern University in the United Kingdom volunteered for participation. Participants provided written informed consent and the study was executed with approval from the local Committee of Research Ethics.

\section{STIMULI CREATION}

Participants were digitally photographed under controlled lighting. Their image was then subjected to a morphing transformation using specialist software (Tiddeman et al., 2001). In order to create the average, morphed image, two-dimensional shapes of the participants' digital photographs were delineated at 179 points using specialist software (Tiddeman et al., 2001). Next the vector differences at each delineation point and an average face template were calculated, which provided a measure of how much each face differed from average. Images were then altered by $50 \%$ of the average face to create self-resembling images. Altering the images by $50 \%$ allows the stimuli to resemble the participant; however, the resemblance is subtle enough that participants do not consciously realize that their face is incorporated in the stimuli. Images were matched as best as possible for luminance and quality using Adobe PhotoShop CS2. Control same- and other-race faces were randomly selected from a freely available database (Minear and Park, 2004) and subjected to similar morphing procedure to retain stimulus consistency and appearance.

\section{POST SCANNING QUESTIONNAIRE}

Immediately following the scanning session participants were asked to complete a questionnaire on the computer to assess their level of needs and distress after playing the Cyberball game (Zadro et al., 2004). All participants were excluded in the last round of the experiment; therefore, they were asked to recall the last game that they played in the scanner and to answer according to their feelings during and after that round of the experiment. The questionnaire contained three manipulation check questions to ensure that participants knew that they were excluded from the game. The questionnaire (Zadro et al., 2004) also contained questions that were designed to assess participants' levels of four basic needs after the game: belonging, control, self-esteem, and meaningful existence and mood. Participants provided their responses on a scale of 1 through 9 ( $1=$ not at all, $9=$ always $)$. In some cases, the questions had to be reverse scored, so that a higher score would be equivalent to a more postive response.

\section{IMPLICIT ASSOCIATION TEST}

Prior to taking part in the study participants were given the implicit association test (IAT; Greenwald et al., 1998) to assess their implicit attitudes towards race. The IAT is a computerized test that uses response time to assess the association between attitude objects and particular evaluations (Dasgupta et al., 2000). In the IAT participants classify information related to racial groups and pleasant and unpleasant attributes. The classification requires participants to use two keys to classify the words and pictures under the categories of White, Black, Pleasant, and Unpleasant. Typically participants perform the task more quickly when the same key classifies the categories of White stimuli and Pleasant stimuli and when Black stimuli and Unpleasant categories are classified using the same key (Dasgupta et al., 2000; Greenwald et al., 1998). The IAT score, or $D$ score, is the contrast between the two stimulus blocks (White + Pleasant and Black + Unpleasant vs White + Unpleasant and Black + Pleasant). Positive $D$ scores point to increasingly positive associations with Black stimuli compared to White stimuli.

\section{IMAGING PROCEDURE AND PARAMETERS}

Participants were scanned using fMRI while they played seven rounds of the virtual ball toss game, Cyberball. Participants were scanned using a Siemens Symphony 1.5 Tesla scanner. Functional images were collected using an EPI sequence $(\mathrm{TR}=3000 \mathrm{~ms}, \mathrm{TE}=45 \mathrm{~ms}$, FOV $192 \times 192 \mathrm{~mm}$, slice thickness $=3.5 \mathrm{~mm}$, gap $=0.5$, number of slices $=35$ ). Participants also underwent a 7 -min structural scan (MPRAGE: 176 slices, TR = $1660 \mathrm{~ms}$, TE = 3.04). Participants were given instruction on how to play Cyberball using an MRI compatible response pad (Current Designs) ${ }^{1}$ and told that during the scan they were going to be playing with two other players, via an Internet connection, located in computer labs at other locations

${ }^{1}$ http://www.curdes.com 
on the university campus (Williams et al., 2000). In actuality the other two players were computerized confederates programmed by the investigators.

In the first three rounds participants played a Cyberball inclusion round with the same-race, other-race, and self-resembling groups (condition order was randomized across participants). In the three following rounds, the same players excluded participants (order also randomized). For the exclusion conditions, the game began as it did in the first three rounds, but as time passed ( $230 \mathrm{~s})$, the other players stopped tossing the ball to the participant. The data were pre-processed and analyzed using FEAT-FSL (Smith et al., 2004) and statistical thresholds were set to cluster corrected $z=2.3$, $p<0.05$ (unless where otherwise stated).

\section{RESULTS}

\section{EFFECT OF EXCLUSION AS A FUNCTION OF FACIAL RESEMBLANCE}

Results indicated that activation in the anterior cingulate cortex (ACC) was highest during the self-resembling and same-race exclusion rounds of the game. We tested the hypothesis that participants would show the greatest level of activation in the dACC when they were excluded (relative to inclusion) during the self-resemblance condition relative to the other conditions (selfresemblance $>$ same-race $>$ other-race). This contrast revealed activation in several areas of the ACC (MNI coordinates: $z=3.64,-2$, $46,12 ; z=3.31,6,44,2 ; z=3.85,16,20,34)$. To further investigate the nature of this relationship we computed an ROI in the dACC and discovered a non-linear (quadratic) relationship that revealed that the ACC was most active to self-resembling and same-race faces relative to other-race faces during exclusion (Figure 1).

\section{EFFECTS OF SELF-REPORTED NEEDS}

We anticipated that participants' self-reported fundamental needs would be affected in the exclusion conditions. In particular, we hypothesized that participants would report a decrease in four fundamental needs as a result of exclusion in the self-resembling condition and that there would be a corresponding increase in ACC activation. We anticipated that activation in the ACC would follow a linear pattern of self-resemblance $>$ same-race $>$ otherrace; instead, results showed a quadratic model was the best fit. Participants exhibited the greatest ACC activation in conjunction with the self-reported distress or impact on fundamental needs when they were excluded in the same-race relative to the other-race

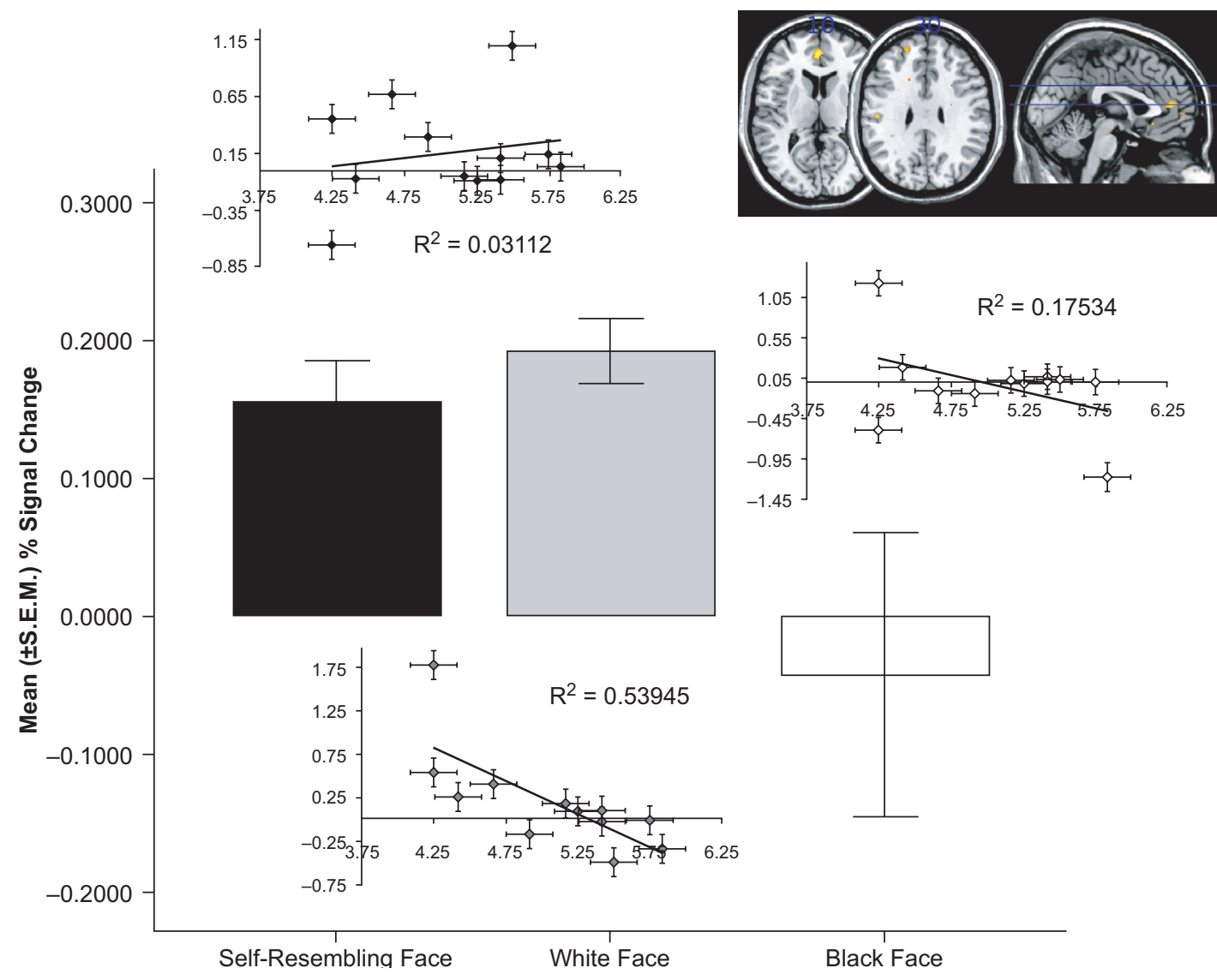

FIGURE 1 | ACC activation to exclusion in the three conditions.

(A) Mean ( \pm SEM) percent signal change and statistical parametric maps for activation in ACC in response to self-resembling condition (black bars),

same-race condition (grey bars), and other-race condition (white bars) during exclusion round. (B) Inlaid plots show the correlation between ACC activation and mean needs. Only the same-race condition (grey diamonds) showed a significant negative correlation with mean needs $[r(11)=-0.734$, $p=0.01$; inlaid plots: black diamonds = self-resembling condition; grey diamonds = same-race condition; white diamonds = other-race condition]. 
and self-resemblance conditions (anterior cingulate gyrus $z=3.5$, $-6,28,24$; posterior cingulate $z=3.49,-4,64,20)$. A correlation between ACC activation and mean needs revealed that in the samerace condition activation in the ACC showed a significant negative correlation with mean needs $[r(11)=-0.734, p=0.01$; Figure 1]. In other words, the less impact that a person felt on their sense of belonging, control, self-esteem, and meaningful existence the less the ACC was activated.

Previous investigations have observed activity in the right ventral prefrontal cortex (RVPFC) during social exclusion (Eisenberger et al., 2003). We discovered correlations between mean needs and percent signal change for ROI's localized to the left VPFC (LVPFC) and RVPFC [also orbital frontal cortex (OFC). We will refer to this area as VPFC.]. There was a trend towards decreased activation in
RVPFC to other-race faces $[r(11)=-0.407, p>0.05]$ and a significant decrease in LVPFC to other-race faces $[r(11)=-0.604, p<0.05$; Figure 2]. Additionally, we tested for an association between the ACC activation with RVPFC and LVPFC activation. Results showed an increase in RVPFC activation as activation in the ACC decreased. This suggests that activation of the RVPFC mitigates the distress response that is activated in the ACC. Our results revealed, however, that activation in the ACC was positively correlated with activation in the LVPFC $(r=0.841 ; p=0.001)$ and RVPFC $(r=0.697$; $p<0.05)$ in the other-race exclusion condition only.

\section{EFFECT OF IMPLICIT RACIAL BIAS}

In our investigation of implicit racial bias (using the IAT) we contrasted self-resembling, same-race, and other-race faces using a
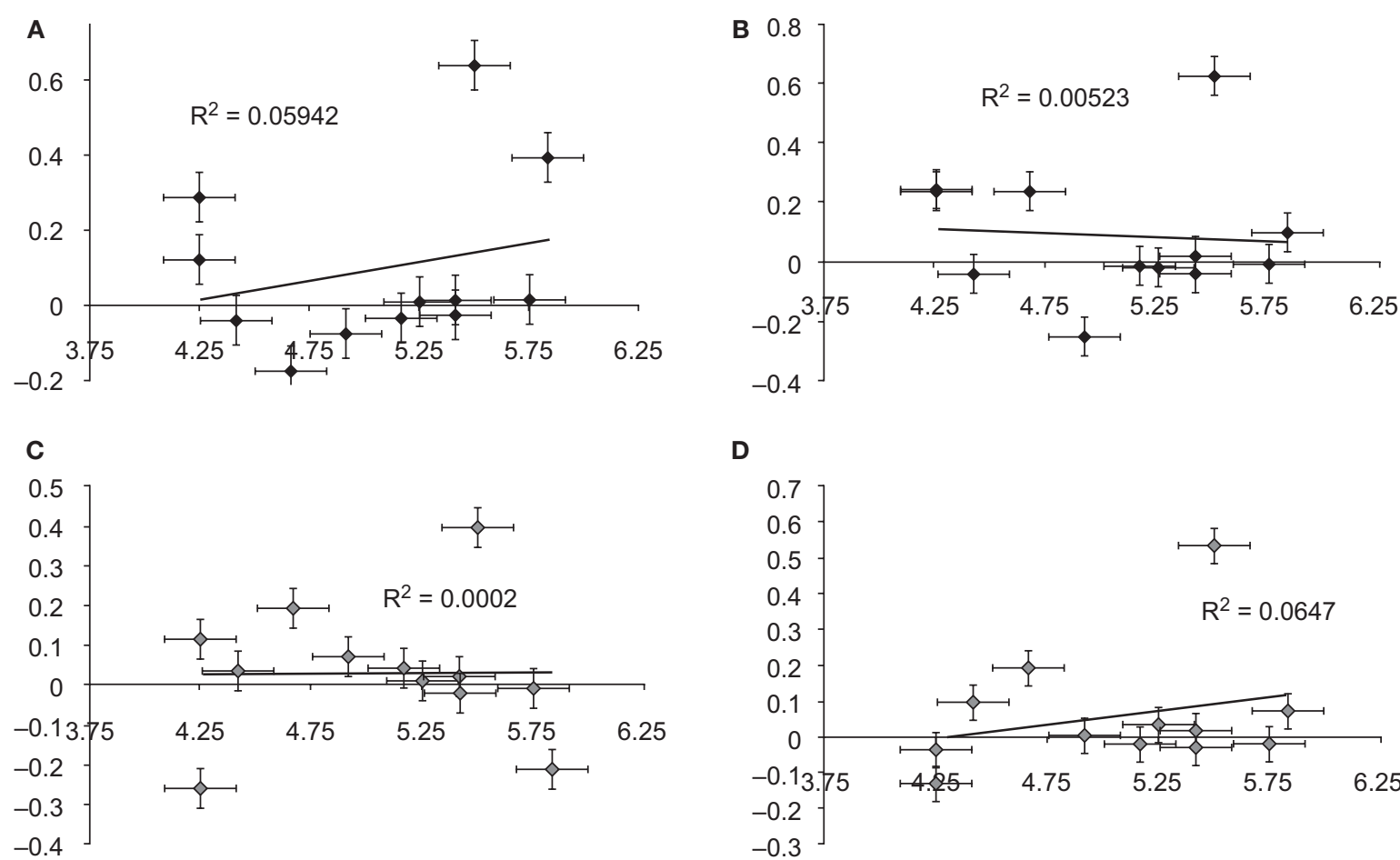

D
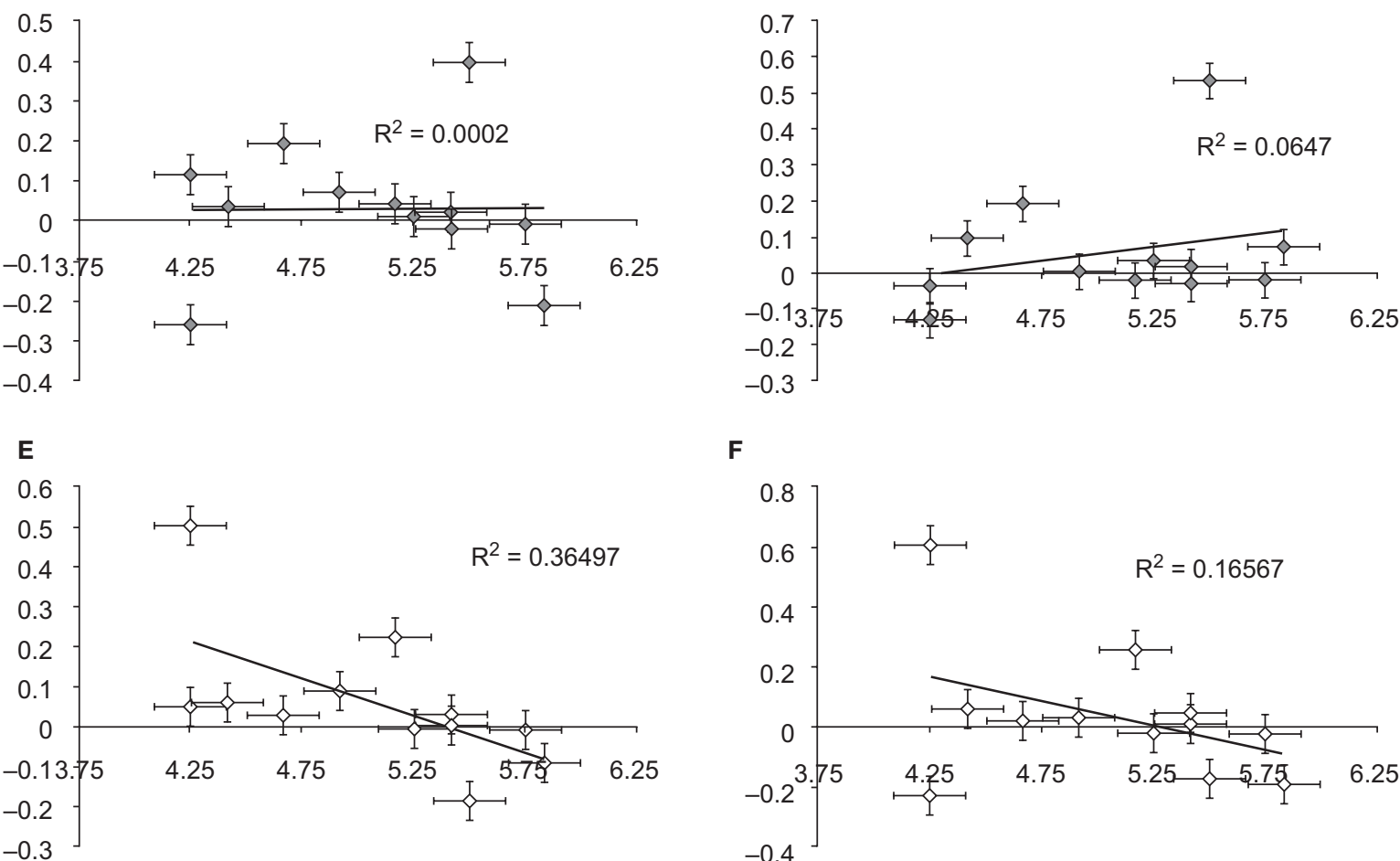

FIGURE 2 | Ventral prefrontal cortex (VPFC) correlation with mean needs. Correlations between mean needs and percent signal change across subjects for ROI's localized to the left and right VPFC. There was a trend for a decrease in right VPFC activation to other-race faces

$\mathbf{F}$

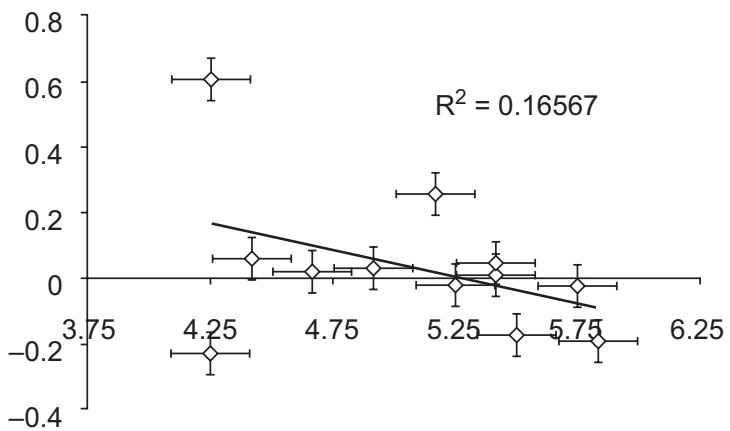

$[r(11)=-0.407]$ and a significant decrease in left VPFC to other-race faces $[r(11)=-0.604, p<0.05)$. (Black diamonds = self-resembling condition; grey diamonds $=$ same-race condition; white diamonds = other-race condition.) 

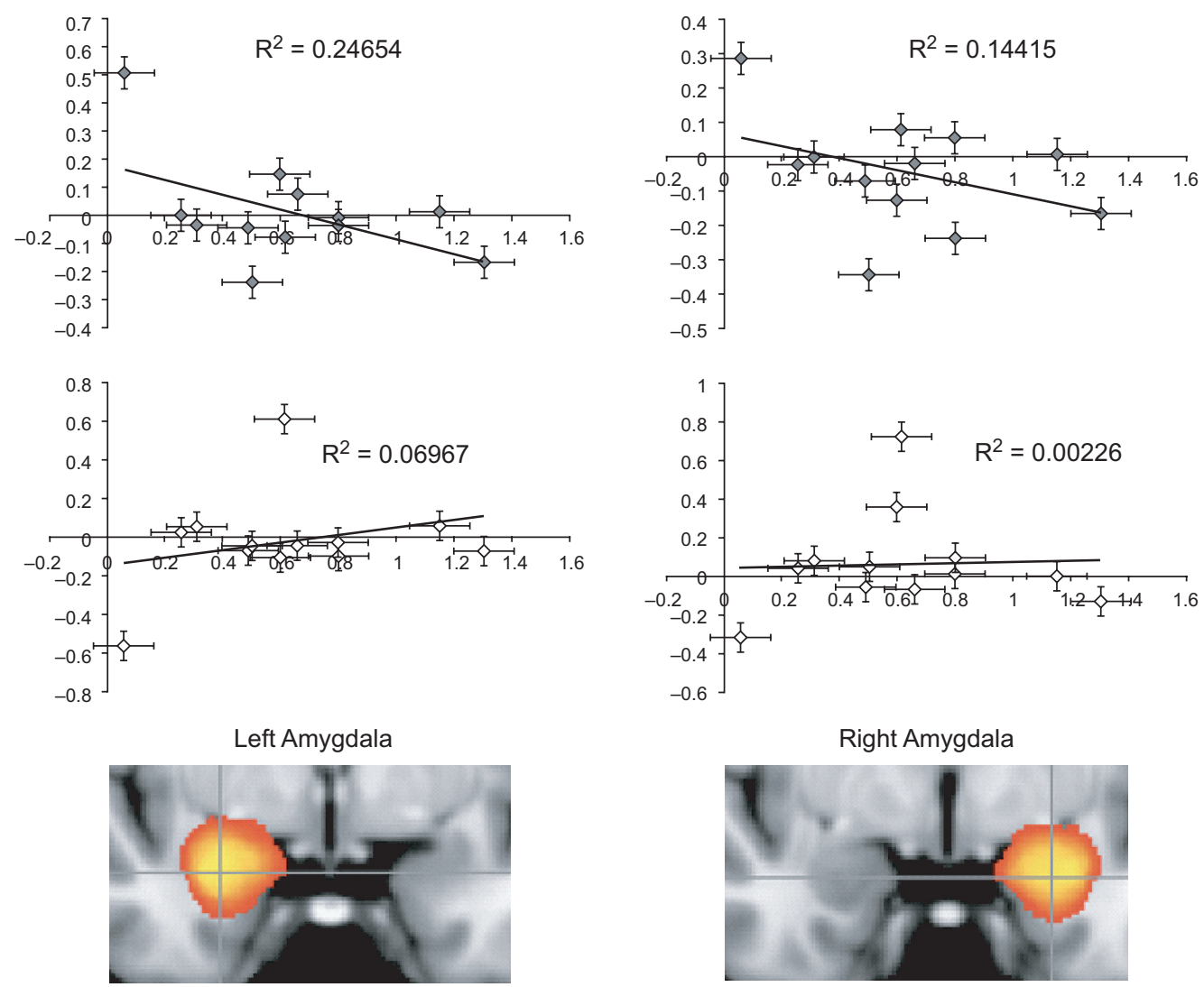

FIGURE 3 | Implicit associations test correlation with amygdala activation Plots show correlations between IAT D scores and percent signal change for ROI's localized to the left and right amygdala. Decreases in left $[r(11)=-0.497$, $p=0.05]$ and right $[r(11)=-0.380, p=0.112]$ amygdala to same-race condition (upper panels/grey diamonds) and only slightly increasing left amygdala activation to other-race condition (lower panels/white diamonds) quadratic model where self- and same-race were predicted to be higher than other-race condition. Analysis revealed that ACC activation was not correlated with amygdala activation and implicit racial bias (IAT score). However, the amygdala correlated positively with the IAT score. This contrast revealed activation in several areas of the brain such as: the left frontal operculum $(z=3.46 ;-46$, $-18,4)$, left postcentral gyrus $(z=3.69 ;-38,-18,38)$, left precentral gyrus $(z=3.16 ;-62,-2,10)$, and the right and left paracingulate gyrus $(z=3.09 ; 0,54,16)$. In a subsequent ROI analysis a correlation between IAT D scores (Greenwald et al., 1998) and percent signal change for ROI's localized to the left $[r(11)=-0.497, p=0.05]$ and right amygdala $[r(11)=-0.380, p=0.112]$ was evident (Figure 3 ). Furthermore, a correlation between ACC activation to same-race and other-race faces as a function of race IAT $D$ score $[r(11)=0.400$, $p=0.09]$ was not significant.

\section{DISCUSSION}

In summary, results indicated that activation in the ACC varies as a function of resemblance to the participant when individuals are excluded. Activation in the ACC increased during exclusion conditions as the other players' facial resemblance to the participants increased. Although we predicted that the activation from the different conditions would fit a linear function (i.e. self-resemblance $>$ same-race $>$ other-race), we found increased activation in the ACC in both the same-race and self-resembling conditions. The activation in the ACC was less during the other-race exclusion condition. This indicates that individuals have a stronger neurological response to exclusion by members of self-referential and same-race in-group. This is not entirely surprising; as past research has suggested that cues of relatedness (self-resemblance and shared ethnicity) engender positive pro-social feelings (DeBruine et al., 2005; Platek et al., 2009; Rushton et al., 1984). Individuals show a preference towards familiar stimuli; which, at the most basic level, would include individuals of the same-race.

We also found that individuals are not only affected neurologically, but participants also reported a decrease in satisfaction of four basic needs (belonging, control, self-esteem, and meaningful existence) when excluded. However, contrary to our prediction, participant's ACC activation showed a correlation to self-reported needs satisfaction in the same-race exclusion condition only. We hypothesized that there would be a correlation among the ACC activation and the self-resembling condition as well. Perhaps selfresembling and other-race faces represent the opposite ends of a self-referential distribution. For instance in the self-resemblance condition, one could be upset by exclusion from this class of stimuli, generally, without evaluation. On the other hand, exclusion by an 
other-race face is not upsetting because this class of stimuli may represent an out-group membership. However, in the same-race condition the players may represent persons who are members of the same social group, and whom might share genes in common with the participant. Perhaps in this instance, in the absence of ostensible cues to relatedness, the emotional feelings about the situation and the person modulate one's reactions to exclusion. That is, the lower individuals' rate their feelings of control and self-esteem, the more it hurts to be excluded by this person. It suggests that exclusion by individuals outside of our kin or other-race groups is modulated by feelings and needs associated with that person or group, but this idea demands more research.

Additionally, we found that activation in the ACC was correlated with activation in the RVPFC and LVPFC during the other-race exclusion condition. We did not predict this activation pattern. We hypothesized that activation in the VPFC would increase as activation in the ACC decreased, particularly during the self-resembling and same-race exclusion conditions. The VPFC is involved in the regulation and inhibition of the social pain response during exclusion(Eisenberger et al., 2003). It is possible that we found a positive correlation between ACC activation and VPFC activation in the other-race condition because activation in the ACC was low to begin with in this condition. Alternatively, perhaps we found different activation patterns between the ACC and the areas of frontal cortex than the previous study (Eisenberger et al., 2003) because we displayed faces to represent the other players. Thus, we may have unwittingly introduced another component that the frontal cortex was attending to in place of mediating ACC activation. Haxby et al. (2002) describe the OFC (which we refer to as VPFC in this paper) as part of a neural system that participates in face perception and discuss its role in evaluating potential reward. This area seems to be instrumental in evaluating the information in faces that is relevant to social reinforcement, such as identity and expression (see Rolls, 1996). It is plausible that VPFC activation was positively correlated with ACC activation in our study, particularly in the other-race condition, because the participants were paying specific attention to and assessing the faces for cues to emotional expression, as well as identity.

Finally, our results supported our hypothesis regarding the IAT and neural activation. Individuals who showed increased positive bias towards same-race images, showed a trend towards increased activation in the left and right amygdala during the other-race exclusion conditions. We also found a significant decrease in amygdala activation in the left amygdala in the same-race exclusion round. This suggests that as IAT score increased (implicit bias

\section{REFERENCES}

Baumeister, R. F., and Leary, M. R. (1995). The need to belong: desire for interpersonal attachments as a fundamental human motivation. Psychol. Bull. $117,497-529$.

Botvinick,M.M., Braver, T.S.,Barch, D. M., Carter, C. S., and Cohen, J. D. (2001). Conflict monitoring and cognitive control. Psychol. Rev. 108, 624-652.

Coghill, R. C., McHaffie, J. G., and Yen, Y. (2003). Neural correlates of interindividual differences in the subjective experience of pain. Proc. Natl. Acad. Sci. U.S.A. 100, 8538-8542.

Cunningham, W. A., Johnson, M. K., Raye, C. L., Gatenby, C. J., Gore, J. C., and Banaji, M. R. (2004). Seperable neural components in the processinf of black and white faces. Psychol. Sci. 15, 806-813.

Daly, M., and Wilson, M. (1982). Whom are new born babies said to resemble? Ethol. Sociobiol. 3, 69-78.

against other-race increased), participants showed a decrease in left amygdala activation when excluded by the same-race faces. This finding supports previous research regarding the importance of the amygdala in response to in- and out-group determinations and judgements (Phelps et al., 2000). Phelps et al. (2000) found that amygdala activation was correlated with both IAT reaction time as well as a startle eye-blink response when white participants were shown black faces. Thus, it appears that the amygdala is a primary component in the neural system involved in the response and appraisal of social groups possibly helping to make determinations regarding social group dynamics (see S.M. Platek and A. Krill, submitted).

Overall, the current results showed that individuals respond differentially to exclusion based upon level of resemblance to oneself and one's same-race group. These findings are significant in understanding how people respond to others in social situations based upon two important social cues: race and kinship. We were unable to test for gender effects. In our study there were only three males; therefore the majority of the participants were females. While we did not anticipate any significant sex effects, as the previous social exclusion literature has not revealed much in the way of sex effects, we cannot rule them out because we were unable to test for them given our sample.

Our results show that sharing race tends to make exclusion a more powerful and negative experience; whereas exclusion by an other-race has less of an impact. Unfortunately, we were not able to identify the mechanisms by which exclusion was more distressing in response to self-resembling and same-race faces. One possibility might involve differences in the feeling of development of a closer bond with the other players during the game. Future researchers could measure the development of a bond, feelings of trust, or positive or negative association feelings towards the other players during the Cyberball game. This would be a fertile area for future research and answer some of the questions left unanswered in our study. Furthermore, an examination of sex differences in social exclusion would also shed some light on an area that we were unable to investigate given our sample.

\section{ACKNOWLEDGEMENTS}

Funding for this work was provided by a grant from the Pioneer Fund, a University of Liverpool faculty induction award, and The School of Biological Sciences at The University of Liverpool. Furthermore, we would like to thank Val Adams for her assistance with this project and the reviewers for their thoughtful comments and suggestions.

Dasgupta, N., McGhee, D. E., Greenwald, A. G., and Banaji, M. R. (2000). Automatic preference for white Americans: eliminating the familiarity explanation. J. Exp. Soc. Psychol. 36, 316-328.

DeBruine, L. M. (2002). Facial resemblance enhances trust. Proc. R. Soc. Lond. B Biol. Sci. 269, 1307-1312.

DeBruine, L. M. (2004). Resemblance to self increases the appeal of child faces to both men and women. Evol. Hum. Behav. 25, 142-154.

DeBruine, L. M., Jones, B. C., and Perrett, D. I. (2005). Women's attractiveness judgments of self-resembling faces change across the menstrual cycle. Horm. Behav. 47, 379-383.

Eisenberger, N. I., Jarcho, J. M., Lieberman, M. D., and Naliboff, B. D. (2005). An experimental study of shared sensitivity to physical pain and social rejection. Pain 126, 132-138. 
Eisenberger, N. I., and Lieberman, M. D. (2004). Why rejection hurts: a common physical alarm system for physical and social pain. Trends Cogn. Sci. 8, 294-300.

Eisenberger, N. I., Lieberman, M. D., and Williams, K. D. (2003). Does rejection hurt? An fMRI study of social exclusion. Science 302, 290-292.

Golby, A. J., Gabrieli, J. D., Chiao, J.Y., and Eberhardt, J. L. (2001). Differential responses in the fusiform region to same-race and other-race faces. Nat. Neurosci. 4, 845-850.

Greenwald, A. G., McGhee, D. E., and Schwartz, J. L. K. (1998). Measuring individual differences in implicit cognition: the implicit association test. J. Pers. Soc. Psychol. 74, 1464-1480.

Hart, A. J., Whalen, P. J., Shin, L. M., McInerney, S. C., Fischer, H., and Rauch, S. L. (2000). Differential response in the human amygdala to racial outgroup vs ingroup face stimuli. Neuroreport 11, 2351-2355.

Haxby, J. V., Hoffman, E. A., and Gobbini, M. I. (2002). Human neural systems for face recognition and social communication. Biol. Psychol. 51, 59-67.

Herrmann, M. J., Schreppel, T., Jäger, D., Koehler, S., Ehlis, A., and Fallgatter, A. J. (2007). The other-race effect for face perception: an even-related potential study. J. Neural Transm. 114, 951-957.

Kim, J. S., Yoon, H. W., Kim, B. S., Jeun, S. S., Jung, S. L., and Choe, B. Y. (2006). Racial distinction of the unknown facial identity recognition mechanism by event related fMRI. Neurosci. Lett. 397, 279-284.

Lieberman, M. D., Hariri, A., Jarcho, J. M., Eisenberger, N. I., and Bookheimer, S. Y. (2005). An fMRI investigation of race-related amygdala activity in African-American and Caucasian-American individuals. Nat. Neurosci. 8, 720-722.
Love, R. (2001). fMRI used to study race effect on face recognition. Lancet 358, 476.

Meissner, C.A., and Brigham, J. C. (2001). Thirty years of investigating the ownrace bias in memory for faces: a metaanalytic review. Psychol. Public Policy Law 7, 3-35.

Minear, M., and Park, D. C. (2004). A lifespan data base of adult facial stimuli. Behav. Res. Methods Instrum. Comput. 36, 630-633.

Ocshner, K. N., Zaki, J., Ludlow, D. H., Knierim, K., Ramachandran, T., Glover, G. H., et al. (2008). Your pain or mine? Common and distinct neural systems suporting the perception of pain in self and other. Soc. Cogn. Affect. Neurosci. 3, 144-160.

Panksepp, J. (2005). Feeling the pain of social loss. Science 302, 237-239.

Phelps, E. A. (2000). Performance on indirect measures of race evaluation predicts amygdala activation. J. Cogn. Neurosci. 12, 729-738.

Phelps, E. A., O'Conner, K. J., Cunningham, W. A., Funayama, E. S., Gatenby, J. C., Gore, J. C., et al. (2000). Performance on indirect measures of race evaluation predicts amygdala activation. J. Cogn. Neurosci. 12, 729-738.

Pinkham,A.E., Sasson, N. J., Calkins, M. E. Richard, J., Hughett, P., and Gur, R. E. (2008). The other-race effect in face processing among African American and Caucasian individuals with schizophrenia. Am. J. Psychiatry 165, 639-645.

Platek, S. M. (2002). Unconcious reactions to children's faces: the effects of resemblance. Evol. Cogn. 8, 207-214.

Platek, S. M., Critton, R. L., Burch, R. L., Frederick, D. A., Myers, T. E., and Gallup, G. G. Jr (2003). How much paternal resemblence is enough? Sex differences in the reaction to resemblance but not in ability to detect resemblance. Evol. Hum. Behav 24 81-87.

Platek, S. M., Keenan, J. P., Gallup, G. G. Jr, and Mohamed, F. B. (2004). Where am I? The neurological correlates of self and other. Brain Res. Cogn. Brain Res. 19, 114-122.

Platek, S. M., Keenan, J. P., and Mohamed, F. B. (2005). Sex differences in the neural correlates of child facial resemblance: an event related fMRI study. Neuroimage 25, 1336-1344.

Platek, S. M., Krill, A. L., and Kemp, S. M. (2008). The neural basis of facial resemblance. Neurosci. Lett. 437 , 76-81.

Platek, S. M., Krill, A. L., and Wilson, B. (2009). Implicit trustworthiness ratings of self-resembling faces activate brain centers involved in reward. Neuropsychologia 47, 289-293.

Platek, S. M., and Thomson, J. W. (2007) Facial resemblance exaggerates sexspecific jealousy-based decisions. Evol. Psychol. 5, 223-231.

Rainville, P., Duncan, G. H., Price, D. D., Carrier, B., and Bushnell, M.D. (1997) Pain affect encoded in human anterior cingulate cortex but not somatosensory cortex. Science $277,968-971$.

Rolls, E. T. (1996). The orbitofrontal cortex. Philos. Trans. R. Soc. Lond. B Biol. Sci. 351, 1433-1444.

Rushton, P., Russell, R. J. H., and Wells, P. A. (1984). Genetic similarity theory: beyond kin selection. Behav. Genet. 14, 179-193.

Smith, S. M., Jenkinson, M., Woolrich, M. W., Beckmann, C. F., Behrens, T. E. J., Johansen-Berg, H., et al. (2004). Advances in functional and structural MR image analysis and implementation as FSL. NeuroImage 23, S208-219.

Stahl, J. W., Kiefer, M., and Bukach, C. M. (2008). Expertise and own-race bias in face processing: an event-related potential study. Neuroreport 19 , 583-587.

Tanaka,J.W., Kiefer, M., and Bukach, C. M. (2004). A holistic account of the own-race effect in face recognition: evidence from a cross-cultural study. Cognition 93, 1-9.

Tiddeman, B., Burt, D. M., and Perret, D. I. (2001). Computer graphics in facial perception research. IEEE Comput. Graph. Appl. 21, 42-50.

Williams, K. (1997). Social ostracism. In Aversive Interpersonal Behaviors, R. M. Kowalski, ed. (New York, Plenum), pp. 133-170.

Williams, K., Cheng, C. K. T., and Choi, W. (2000). Cyberostracism: effects of being ignored over the internet. J. Pers. Soc. Psychol. 79, 748-762.

Zadro, L., Williams, K., and Richardson, R. (2004).How low can you go? Ostracism by a computer is sufficient to lower selfreported levels of belonging, control, self-esteem, and meaningful existence. J. Exp. Soc. Psychol. 40, 560-567.

Conflict of Interest Statement: The authors declare that the research was conducted in the absence of commercial or financial relationships that could be construed as a potential conflict of interest.

Received: 21 November 2008; paper pending published: 6 February 2009; accepted: 20 February 2009; published online: 13 April 2009.

Citation: Krill A and Platek SM (2009) In-group and out-group membership mediates anterior cingulate activation to social exclusion. Front. Evol. Neurosci. (2009) 1:1. doi: 10.3389/neuro.18.001.2009 Copyright (c) 2009 Krill and Platek. This is an open-access article subject to an exclusive license agreement between the authors and the Frontiers Research Foundation, which permits unrestricted use, distribution, and reproduction in any medium, provided the original authors and source are credited. 